\title{
The P3 Protein of Turnip mosaic virus Can Alone Induce Hypersensitive Response-Like Cell Death in Arabidopsis thaliana Carrying TuNI
}

\author{
Bo Min Kim, ${ }^{1}$ Noriko Suehiro, ${ }^{2}$ Tomohide Natsuaki, ${ }^{2}$ Tsuyoshi Inukai, ${ }^{1}$ and Chikara Masuta ${ }^{1}$ \\ ${ }^{1}$ Graduate School of Agriculture, Hokkaido University, Sapporo 060-8589, Japan; ${ }^{2}$ Faculty of Agriculture, Utsunomiya \\ University, Mine-machi 350, Utsunomiya 321-8505, Japan
}

Submitted 13 July 2009. Accepted 22 September 2009.

\begin{abstract}
Strains TuR1 and TuC of Turnip mosaic virus (TuMV) induce different symptoms on Arabidopsis thaliana ecotype Landsberg erecta (Ler); plants infected with TuR1 develop systemic necrosis, while TuC causes mosaics. We previously found that the Ler systemic necrosis was controlled by a single dominant gene, TuNI (TuMV necrosis inducer), and that it was actually a form of host defense response leading to a hypersensitive reaction (HR)-like cell death. To identify the viral factor interacting with $T u N I$, the domain swapping between the genomic clones of TuR1 and TuC was carried out, and we identified the TuMV symptom determinant interacting with $\mathrm{TuNI}$ as the P3 gene. Moreover, it was found that the central 0.5-kb domain of P3, including three different amino acids between the two isolates, was responsible for the systemic HR. To verify that the P3 gene can alone induce necrosis, we analyzed the constitutive P3 expression in Ler transgenic plants and the transient $\mathrm{P3}$ expression in Ler protoplasts. These results indicated that P3 alone caused HR-like cell death. In this study, we successfully demonstrated that the systemic necrosis by TuMV in Arabidopsis was determined by the gene-for-gene interaction between TuNI and P3 using the protoplast system for direct verification.
\end{abstract}

Turnip mosaic virus (TuMV) belongs to the genus Potyvirus in the family Potyviridae, which is the largest genus and family in plant viruses (Shukla et al. 1994; Ward et al. 1995). TuMV, which has a wide host range, infects many economically important plants, including Brassica crops (Tomlinson 1987; Shukla et al. 1991; Shattuck 1992; Walsh and Jenner 2002), and often causes distinct symptoms such as mosaic and necrosis, depending on the genotypes of both host species and TuMV (Jenner et al. 2000; Walsh et al. 2002; Kaneko et al. 2004) or environmental factors (Kim et al. 2008). Although the control of type and degree of such symptoms by TuMV infection is agriculturally important, the mode of interaction between host and virus factors inducing those symptoms was not well elucidated. We previously reported that Arabidopsis thaliana ecotype Landsberg erecta (Ler) developed necrosis after infection with TuMV-TuR1 whereas Columbia (Col-0) developed mosaic. The necrosis symptom in Ler was induced by the interaction between a dominant gene, TuNI, in Ler and

Corresponding author: C. Masuta; E-mail: masuta@res.agr.hokudai.ac.jp

* The $\boldsymbol{e}$-Xtra logo stands for "electronic extra" and indicates that two supplementary figures are published online. virus factors in TuMV-TuR1 (Kaneko et al. 2004). Our study also showed that the Ler necrosis induced by TuR1 was actually programmed cell death (PCD) that accompanies defense reactions such as generation of hydrogen peroxide $\left(\mathrm{H}_{2} \mathrm{O}_{2}\right)$, the accumulation of salicylic acid (SA), the emission of ethylene, and the expression of pathogenesis-related (PR) genes (Kim et al. 2008). The hypersensitive reaction (HR) is the PCD that is induced by the interaction between a plant resistance $(R)$ gene and an avirulence factor of a pathogen. Because the features of the Ler necrosis were similar to those of HR, the necrosis was considered to be a form of HR (Kaneko et al. 2004; Kim et al. 2008). This evidence mean that the systemic necrosis can be explained based on the gene-for-gene hypothesis as well documented for $R$-gene-mediated resistance reactions. Therefore, our next question is whether a single gene product in TuR1 can alone induce necrosis in Ler.

The TuMV genome is approximately 9,830 nucleotides long and has a single open reading frame (ORF) flanked by two untranslated regions (Walsh and Jenner 2002). The ORF is translated into a single polyprotein and, via the three virus-encoded proteases, it is processed into 10 proteins: $\mathrm{P} 1$, helper component protease (HC-Pro), P3, 6K1, cytoplasmic/cylindrical inclusion $(\mathrm{CI}), 6 \mathrm{~K} 2$, virus-encoded genome linked (VPg) protein, nuclear inclusion proteins $a$ and $b$ (NIa and NIb), and the coat protein (CP) (Walsh and Jenner 2002). Recently, it was also reported that the new coding sequence PIPO existed within the sequence of the $\mathrm{P} 3$ gene in the +2 reading-frame (Chung et al. 2008). For Potyvirus spp., viral proteins such as HC-Pro, P3, $\mathrm{CI}$, and $\mathrm{CP}$ have been identified as virulence and avirulence determinants (Gal-On 2000; Sáenz et al. 2000, 2001; Redondo et al. 2001; Jenner et al. 2002, 2003; Suehiro et al. 2004). In the pathosystem of TuMV and Brassica napus, P3 and CI have been identified as the avirulence determinants for $R$ genes TuRBO3 and TuRB04, and TuRBO1 and TuRBO5, respectively (Jenner et al. 2002, 2003). The TuMV construct with a point mutation in P3 overcame the resistance of the B. napus line $22 \mathrm{~S}$ carrying $T u R B 03$ and the reaction of $22 \mathrm{~S}$ was changed from resistance to systemic necrosis by the mutation of P3. This indicated that the avirulence factor P3 also could induce necrotic symptoms (Jenner et al. 2003). CI was also found to have the dual role as the avirulence and symptom determinant (Jenner et al. 2000). In soybean, the elicitor function of Soybean mosaic virus (SMV) that induces Rsv1-mediated extreme resistance and a lethal systemic HR has been mapped to the P3 gene (Hajimorad et al. 2005).

In this study, we mapped the determinant for systemic necrosis to P3 by creating chimeric viruses between TuR1 and TuC causing mosaic symptom in Ler and demonstrated that P3 
alone was actually the symptom determinant interacting with TuNI by transient and stable expressions of P3 in Arabidopsis.

\section{RESULTS}

To identify the symptom determinant or determinants of TuMV interacting with $T u N I$, we performed domain swapping to generate a series of chimeric constructs between the TuMV isolates TuR1 and TuC. TuR1 and TuC were originally isolated from radish and cabbage, respectively. The two isolates share 96 and 97\% identities at the nucleotide and amino acid sequence levels, respectively (Suehiro et al. 2004). TuR1 induced systemic veinal necrosis in Ler, while Ler developed mosaic after TuC infection (Fig. 1), and both isolates caused mosaic in the Arabidopsis ecotype Col-0 without TuNI (Kaneko et al. 2004). The TuMV genome was divided into four parts and then the four chimeric constructs between TuR1 and TuC (R1C-CI:6K2, C-R1-CI:6K2, R1-C-P3, and C-R1-P3) were first tested (Fig. 2A). Only C-R1-P3, which was the TuC construct, contained the P3 gene derived from TuR1 and induced necrosis in Ler, whereas none of the constructs induced necrosis in Col-0 (Fig. 2A; Supplementary Fig. S1). C-R1-P3 had the C terminal of HC-Pro and the $\mathrm{N}$ terminal of $6 \mathrm{~K} 1$ but no differences in amino acid sequence existed in the regions between TuR1 and TuC. These results indicated that the viral genome responsible for systemic necrosis in Ler was the P3 gene. Next, the region of 2,491 to 3,680 nucleotides (nt) containing P3 was divided into three parts, and six chimera were tested (Fig. 2A). The replacement of the $\mathrm{N}$-terminal half of the 0.5 $\mathrm{kb}$ fragment in $\mathrm{P} 3$ of $\mathrm{TuC}$ with that of TuR1, creating C-R1 (2,491 to $2,995 \mathrm{nt})$, was enough to induce necrosis. Conversely, the introduction of the corresponding fragment of $\mathrm{TuC}$ in TuR1, generating R1-C (2,491 to 2,995 nt), resulted in the induction of mosaic symptoms. When the amino acid sequences of the identified domain, which corresponded to the N-terminal half of the P3 protein, were compared between the necrotic isolates (TuR1 and Azu) and the mosaic isolates (TuC, Tu2R2, and $\mathrm{C} 42 \mathrm{~J}$ ), four amino acids were common in the necrotic isolates but different between the necrotic isolates and TuC (Fig. 2B). Among them, three amino acid residues (positions 121,
126, and 127) are closely concentrated in the central region (Fig. 2B). The alteration of the amino acid from $\mathrm{S}$ to $\mathrm{N}$ at position 11 in the TuC background did not induce necrosis, and the reciprocal alteration from $\mathrm{N}$ to $\mathrm{S}$ in the TuR1 background still induced necrosis. Thus, these results of site-directed mutagenesis indicated that the amino acid residues controlling the systemic necrosis reside in the central domain of the P3 protein.

To confirm that the P3 gene is, indeed, the determinant for TuNI, we generated transgenic Arabidopsis plants that express the P3 gene. The cDNA of the P3 gene from TuR1 was cloned into the multiple cloning site downstream of the heat-shock promoter (HSP) 18.2 in the binary vector pTT101 (Takahashi et al. 1992) to create HSP-P3 (Fig. 3A) because we thought that any constitutive expression of the P3 gene in Ler might cause lethal necrosis before we obtained the seedlings. Ler plants were transformed with HSP-P3, and three transgenic $\mathrm{T}_{1}$ plants were obtained (Ler-P3-1 to Ler-P3-3). However, two of them (Ler-P3-2 and Ler-P3-3) showed severe yellowing at the early seedling stage without heat-shock treatment and eventually died. Only Ler-P3-1 could survive, although stunted regardless of heat-shock treatment, and internode elongation was also retarded (Fig. 4A and B). The flower buds in the main stems developed yellowing and wilting, and many of them eventually died, as did the Ler plants infected with TuR1 (Fig. 4D). Although Ler-P3-1 did not develop the typical systemic necrosis at the seedling stage, necrotic spots were observed on the cauline leaves (Fig. 4C). Quantitative real-time reversetranscription polymerase chain reaction (RT-PCR) for Ler-P3-1 at the $\mathrm{T}_{2}$ generation showed that HSP 18.2 was leaky and, without heat-shock treatment, the introduced P3 gene was expressed to $60 \%$ compared with the expression level under heat-shock treatment (Fig. 3B). This seemed to be the reason why, without heat-shock treatment, all transgenic plants obtained showed yellowing with necrosis and often died. When PRI expression was measured by quantitative RT-PCR to assess whether HRlike cell death was induced in Ler-P3-1 in the interaction between $P 3$ and TuNI, we confirmed that the transcription level of the PRI gene was elevated in the transgenic plant, and it was enhanced further by heat-shock treatment (Fig. 4E). As a

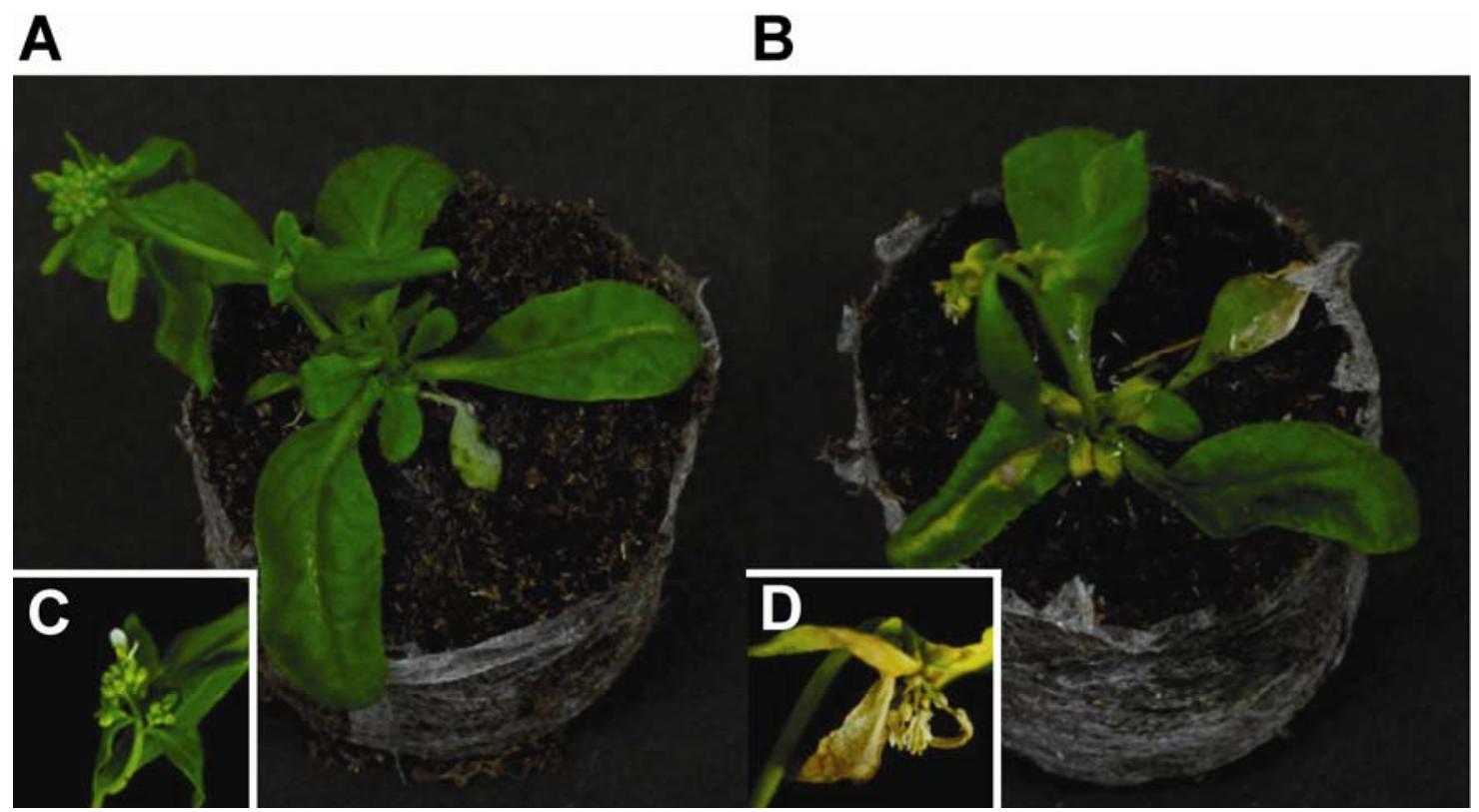

Fig. 1. Symptoms on Arabidopsis thaliana ecotype Landsberg erecta (Ler) inoculated with Turnip mosaic virus (TuMV) isolates TuC or TuR1. A and C, Mosaic symptoms in Ler plants infected with TuMV-TuC. B and D, Necrotic symptoms in Ler plants infected with TuMV-TuR1. Photographs were taken 2 weeks after inoculation. 
control, we also created 12 transgenic Col- 0 lines that express the P3 gene of TuR1 (Col-P3-1 to Col-P3-12). Col-0 nontransgenic plants do not have TuNI and developed mosaic symptoms after TuR1 infection. As expected, those lines all grew normally and did not have any abnormal phenotypes, including necrosis and elevated levels of the $P R l$ gene (data not shown).
To test whether the P3 gene can function as a necrosis-inducing factor interacting with TuNI even at the single-cell level, we successfully developed an assay using Arabidopsis protoplasts. We introduced each plasmid, containing either the entire TuR1 genome or the P3 gene of TuR1, into protoplasts prepared from 4-week-old Arabidopsis leaves. At $20 \mathrm{~h}$ after transfection, Evans

A

TuR1

TuC

R1-C-Cl: 6K2

C-R1-Cl: 6K2

R1-C-P3

C-R1-P3

C-R1(2491-2995)

C-R1(2995-3305)

C-R1(3305-3680)

R1-C(2491-2995)

R1-C(2995-3305)

R1-C(3305-3680)

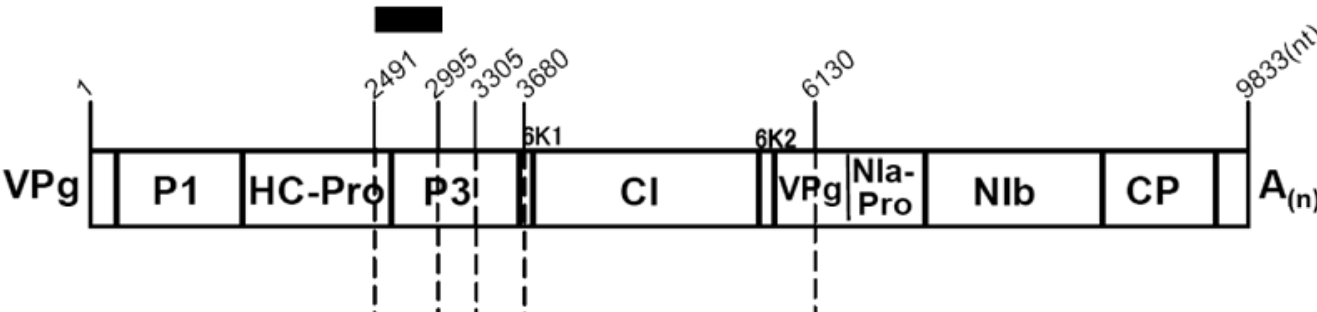

$\frac{\text { phenotype }}{\text { Ler Col-0 }}$

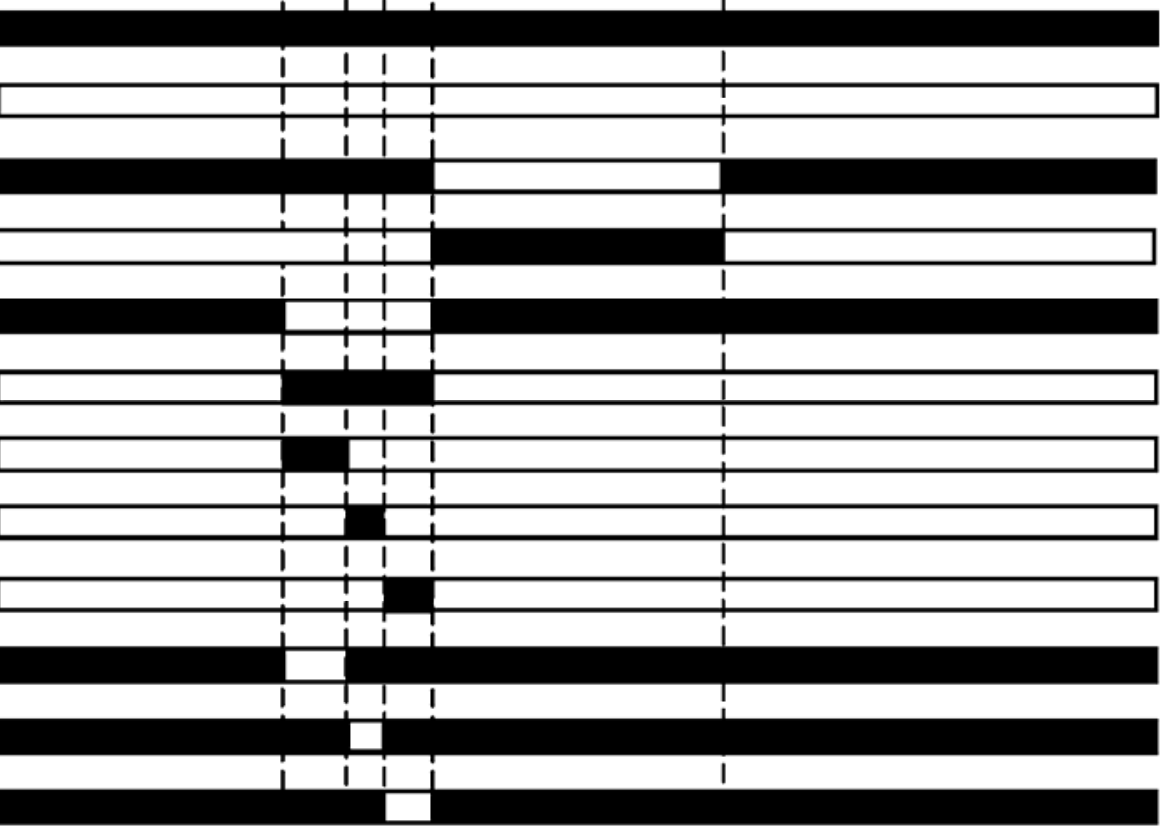

N M

$\mathrm{N} \quad \mathrm{M}$

M M

M M

$\mathrm{N} \quad \mathrm{M}$

$\mathrm{N} \quad \mathrm{M}$

M M

M M

M M

$\mathrm{N} \quad \mathrm{M}$

$\mathrm{N} \quad \mathrm{M}$

B

N [ TUR1 GTEWEDTHGFNNIDDPQWCIKRLIKGVYRPKKLKEDMLANPFLPLYALLSPGVILAFYNS

AZU GTEWEDTHGFNNIDDPQWCIKRLIKGVYRPKQLKEDMLANPFLPLYALLSPGVIMAFYNS

$M\left[\begin{array}{ll}\text { TuC } & \text { GTEWEDTHGA SNIDNPQWC IKRLIKGVYRPKQLKEDMLANPFLPLYALLSPGVILAFYNS } \\ \text { Tu2R2 GTAWEEAHGF|KNIDDPQWCIKRLIQGVYRPKKLREDMLTNPFLPLYALLSPGVILAFYNS }\end{array}\right.$

C42J GTEWEDTHGANNIDDPQWCIKRLIKGVYRPKQLKEDMLANPFLPLYALLSPGVILAFYNS

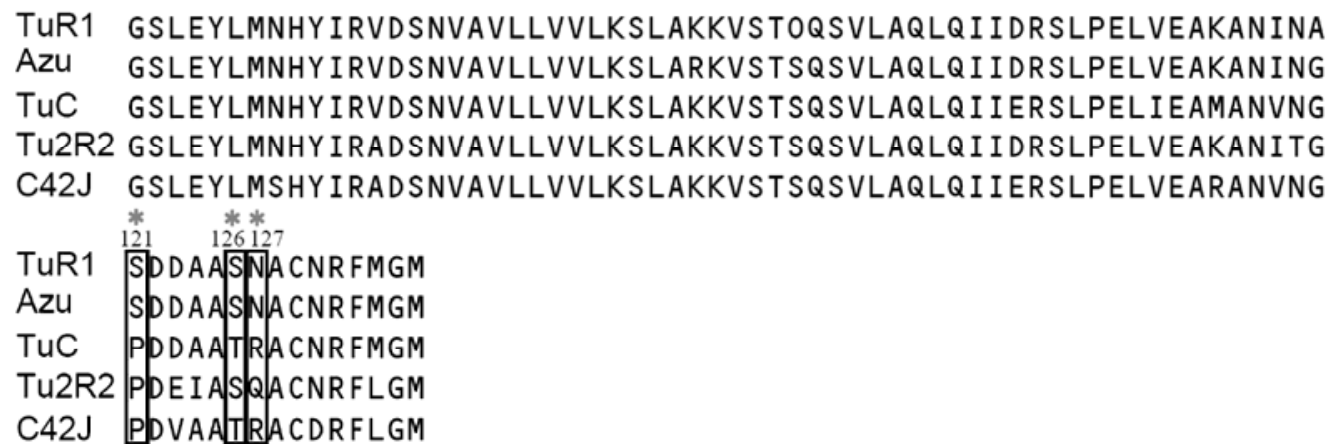

Fig. 2. Symptom induction by the chimeric constructs between Turnip mosaic virus (TuMV) isolates TuR1 and TuC. A, Schematic representation of the parental TuMV isolates and chimeric viruses. The sequence domains of TuR1 and TuC are indicated by black and white boxes, respectively. Chimeric viruses show either mosaic or necrotic symptoms in Arabidopsis thaliana ecotype Landsberg erecta (Ler) while they show only mosaic symptoms in Columbia (Col0). Symptoms were assessed 2 weeks after inoculation. Infection with these viruses was confirmed by tissue print blotting. The black box above the viral genome is the region shown in B. The phenotype of each construct was shown to the right. N, necrosis; M, mosaic. B, Comparison of amino acid sequences of the N-terminal half of the P3 protein (1 to 135) among the TuMV isolates TuR1, Azu, TuC, Tu2R2, and C42J. TuR1 and Azu cause necrotic symptoms (N) in Ler, while TuC, Tu2R2, and C42J induce mosaic symptoms (M) in Ler plants. Asterisks indicate the amino acid residues that are conserved only among the necrosis-inducing isolates. 
blue was used to stain any dead cells. The TuR1 genome and the P3 similarly induced cell death in the Ler protoplasts but not in the Col-0 cells (Fig. 5A and B), suggesting that the P3 gene alone can induce cell death of Ler. There is no correlation between cell death and viral concentration because TuR 1 accumulated to a similar level in protoplasts of Ler and Col-0 (Supplementary Fig. S2). Because the expression of the PRl gene is the hallmark of a resistance reaction, we measured the expression levels of the PRI gene in the protoplasts in which the P3 gene was introduced. The results of quantitative RT-PCR showed that both the TuR1 genome and the P3 gene elevated the levels of the $P R l$ gene (Fig. 5C). We then measured $\mathrm{H}_{2} \mathrm{O}_{2}$ in the protoplasts in which the $\mathrm{P} 3$ gene was introduced because HR-like cell death was always associated with $\mathrm{H}_{2} \mathrm{O}_{2}$ accumulation. $\mathrm{H}_{2}$ DCFDA ( $2^{\prime} 7^{\prime}$-dichlorofluorescin diacetate) was used as a probe for intracellular hydrogen peroxide to monitor $\mathrm{H}_{2} \mathrm{O}_{2}$ accumulation by microscopy. At various times, we transfected Ler protoplasts with either the TuR1 genome or the P3 gene of TuR1. Both the TuR1 genome and the P3 gene markedly elevated the levels of $\mathrm{H}_{2} \mathrm{O}_{2}$ accumulation at $4 \mathrm{~h}$ (Fig. 5D). By contrast, we did not observe any detectable $\mathrm{H}_{2}$ DCFDA signal in the Ler protoplasts transfected with the control plasmid containing the green fluorescent protein (GFP) gene. When Col-0 protoplasts were used, we did not observe $\mathrm{H}_{2} \mathrm{O}_{2}$ accumulation in any samples. These results suggest that the $\mathrm{P} 3$ gene alone can induce HR-like cell death by generating $\mathrm{H}_{2} \mathrm{O}_{2}$ at the single-cell level in Ler and, thus, the observed systemic necrosis is actually systemic HR.

\section{DISCUSSION}

In this article, we identified P3 as a single viral factor inducing systemic HR by the interaction with TuNI. This indicated that the necrotic symptoms caused in Arabidopsis infected by
TuMV was actually induced based on the gene-for-gene relationship between host and virus factors. Our P3 domain-swapping experiments indicated that the $\mathrm{P} 3$ central domain containing three different amino acids (residues 121, 126, and 127) between the two TuMV genomes (TuR1 and TuC) might be involved in induction of systemic HR. In the P3 sequence of TuMV, the coding sequence of PIPO was found in the different reading frame (Chung et al. 2008). However, because the P3 domain responsible for the induction of systemic HR is located upstream of PIPO, it seems that PIPO is not involved in the symptom induction.

Intriguingly, a very similar observation on the P3 elicitor functions for systemic HR has been demonstrated in the pathosystem of another Potyvirus sp., SMV with Rsvl-genotype soybean; the soybean symptom was reported as a lethal systemic HR (LSHR) (Hajimorad et al. 2005, 2006, 2008). For the pathosystem of TuMV and B. napus, TuMV P3 has been identified as the avirulent determinant for the $R$ gene TuRBO3 (Jenner et al. 2003). When the TuRBO3 plants were inoculated with the infectious TuMV clones containing the mutation in the amino acids of P3, they also observed systemic necrotic infection as well as extreme resistance, analogous to our observation (Jenner et al. 2003). Thus, we consider that this systemic necrosis may be an HR-like cell death similar to those we observed in the pathosystem of TuMV and TuNI-Arabidopsis. P3 is one of the least-conserved proteins among Potyvirus spp. and, thus, it is difficult to imagine that different P3 proteins may share a similar tertiary structure beyond different Potyvirus spp. However, it may be simplistic to consider these observations coincident. If P3 structures are conserved primarily for those interactions with host factors that control $R$-genemediated resistance, it is conceivable that $\mathrm{P} 3$ proteins essentially function as an elicitor for resistance or even systemic HR; it

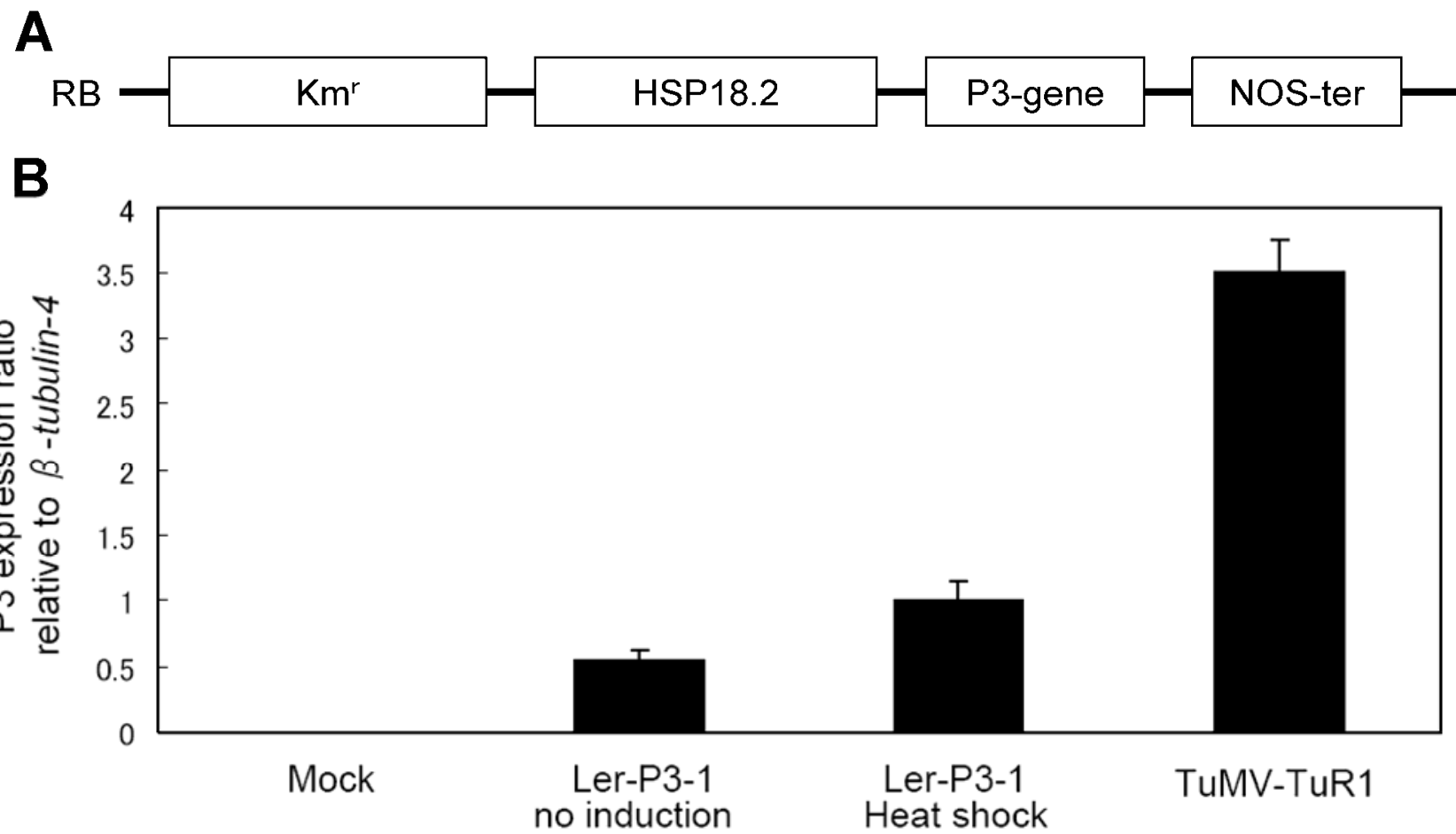

Fig. 3. Expression of the P3 gene in the Arabidopsis thaliana transgenic plant line (A. thaliana ecotype Landsberg erecta [Ler]-P3-1). A, Schematic representation of the binary plasmid pTT101 used for Agrobacterium spp.-mediated plant transformation. The cDNA sequence encoding the P3 gene of Turnip mosaic virus (TuMV) isolates TuR1 was cloned downstream of the heat-shock promoter 18.2 (HSP 18.2). RB, right border LB, left border; Km ${ }^{\mathrm{r}}$, neomycin phosphotransferase gene; NOS-Ter, nopaline synthase terminator. B, Accumulation of messenger RNA (mRNA) for the P3 gene in Ler-P3-1. Real-time reverse-transcription polymerase chain reaction was performed to determine the expression level of P3. Heat-shock treatment was the three times incubation at $37^{\circ} \mathrm{C}$ for $3 \mathrm{~h}$ every third day for 4 -week-old plants. TuMV-TuR1 was inoculated onto 4-week-old Ler plants. Total RNA was extracted from 6-week-old Ler-P3 plants or Ler plants 2 weeks after inoculation with TuMV-TuR1. Relative expression levels were normalized with respect to the $\beta$-tubulin- 4 mRNA level. Three replicates of the analysis were done. Error bars represent standard error of the mean $(n=3)$. 

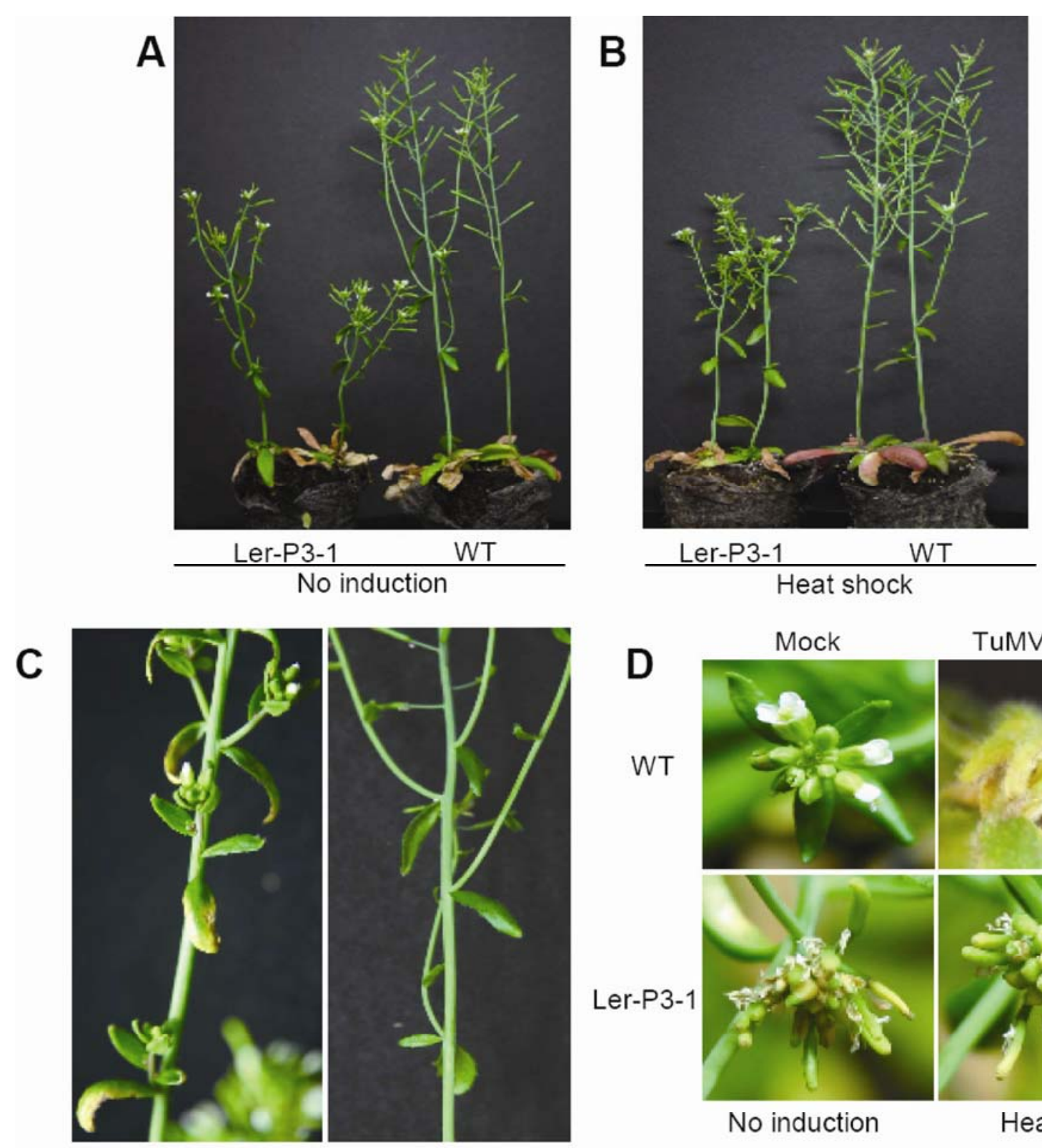

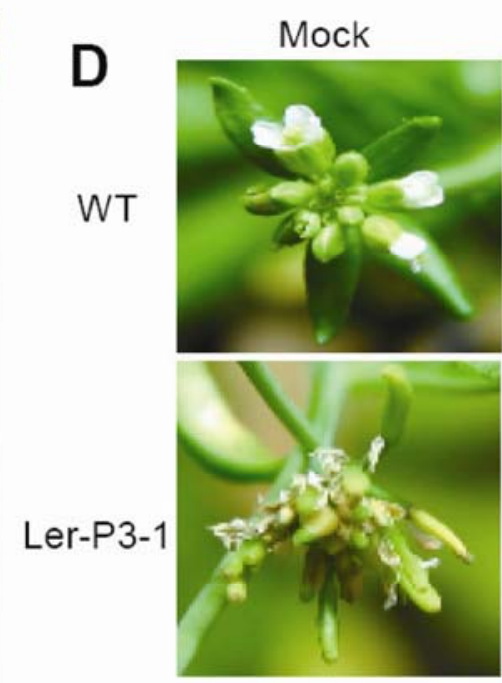

No induction
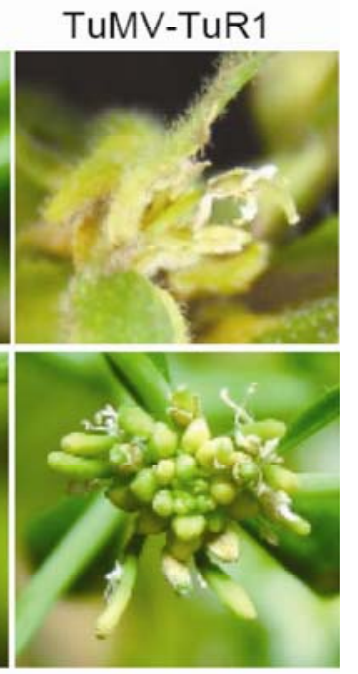

Heat shock

WT

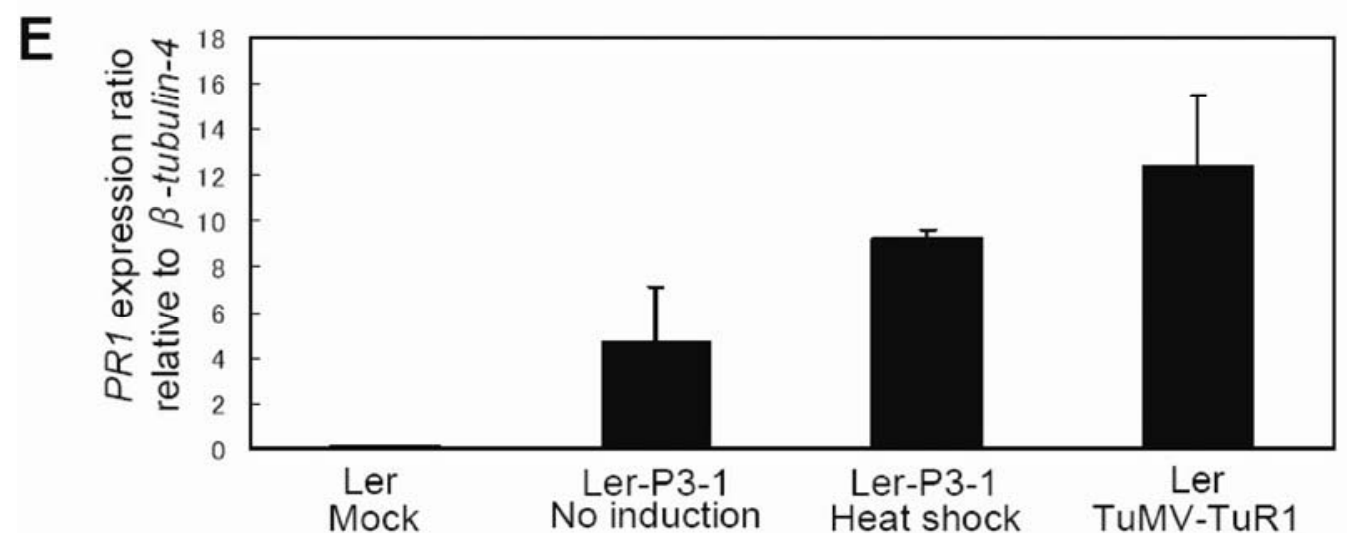

Fig. 4. Phenotypic changes of the Arabidopsis thaliana ecotype Landsberg erecta (Ler)-P3 transgenic plant line (Ler-P3-1). A and B, Phenotype of Ler-P3-1. Four-week-old plants were incubated three times at $37^{\circ} \mathrm{C}$ for $3 \mathrm{~h}$ every third day. $\mathbf{C}$, Leaf symptoms on Ler-P3-1 expressing the P3 gene after heat-shock treatment. Photographs were taken 6 weeks after sowing. D, Flower symptoms. Ler after heat-shock treatment (upper left). Ler infected with Turnip mosaic virus (TuMV)-TuR1 (upper right). Ler-P3-1 (lower left). Ler-P3-1 after heat-shock treatment (lower right). E, Expression level of PR1 by quantitative reverse-transcription polymerase chain reaction. Total RNA was extracted from mock-treated Ler, Ler-P3-1, heat-shock-treated Ler-P3-1, and TuMV-TuR1infected Ler. Relative expression levels were normalized with respect to the $\beta$-tubulin- 4 mRNA level. Three replicates of the analysis were done. Error bars represent standard error of the mean $(n=3)$. 


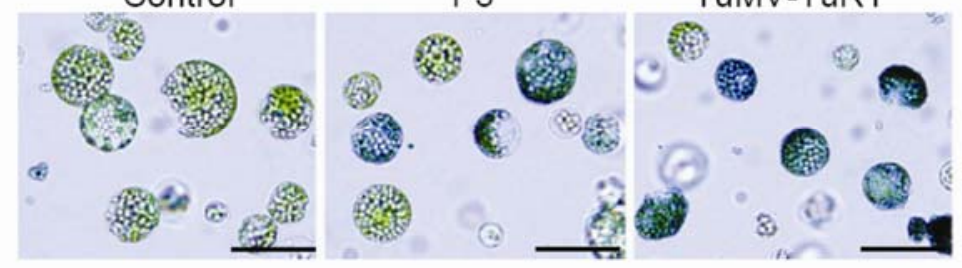

B

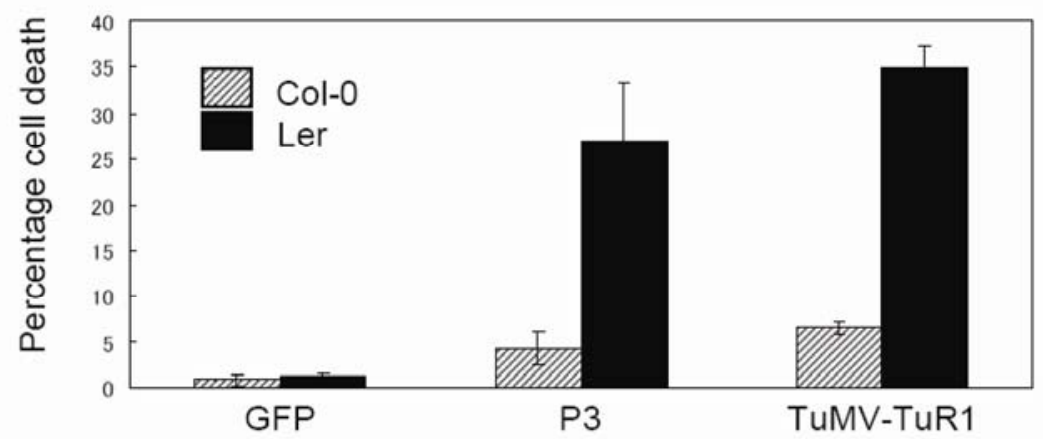

C

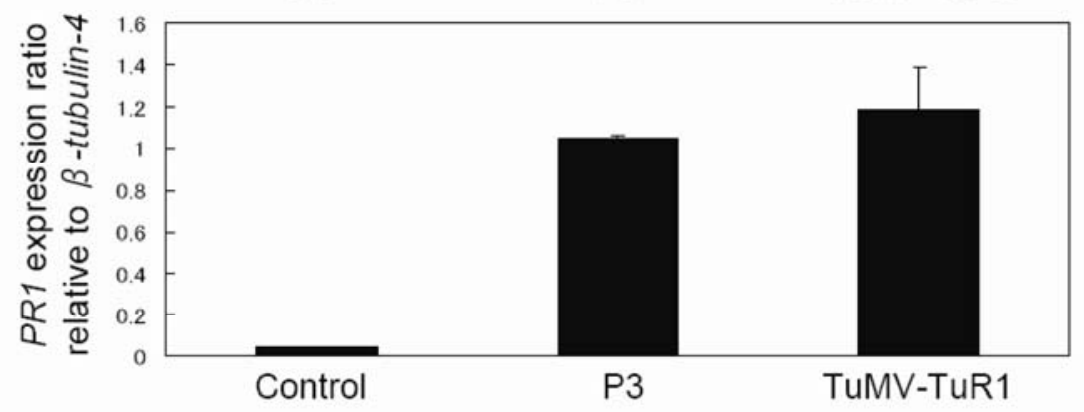

D

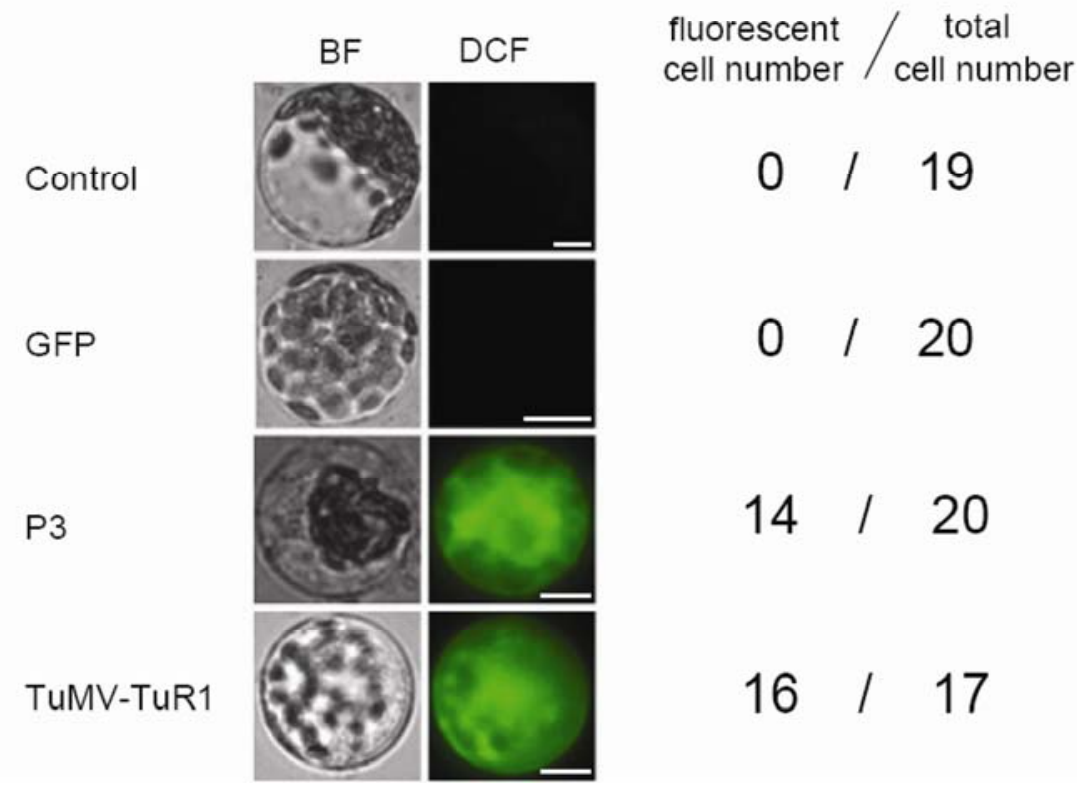

Fig. 5. Cell death of Arabidopsis thaliana ecotype Landsberg erecta (Ler) protoplasts transfected with either P3 or Turnip mosaic virus (TuMV)-TuR1. A, Cell death of Ler protoplasts transfected with either P3 or TuMV-TuR1. At $20 \mathrm{~h}$ after transfection, $0.04 \%$ Evans blue was added to the samples. Control Ler protoplasts were treated with distilled water (D.W.). Protoplasts were prepared from 4-week-old Ler plants. Bars $=50 \mu \mathrm{m}$. B, Cell death of Columbia (Col-0) and Ler protoplasts transfected with either P3 or TuMV-TuR1. The protoplasts from Col-0 and Ler were transfected with green fluorescent protein (GFP) (control), P3, or TuMV-TuR1. At $20 \mathrm{~h}$ after transfection, the samples were stained with $0.04 \%$ Evans blue for 5 min. Cell death was scored using a light microscope. Data are presented as a percentage of cell death after subtraction of the control percentage as the background. Protoplasts were prepared from 4-week-old Ler and Col-0 plants. The rates of transfection efficiency were approximately equal between Col- 0 and Ler (60 to $62 \%)$. Three replicates of the analysis were done. Error bars represent standard error of the mean $(n=3)$. C, Expression level of $P R 1$ by quantitative reverse-transcription polymerase chain reaction. Total RNA was extracted from protoplasts $20 \mathrm{~h}$ after transfection. Relative expression levels were normalized with respect to the $\beta$-tubulin-4 mRNA level. The protoplasts were prepared from 4-week-old Ler plants. Three replicates of the analysis were performed. Error bars represent standard error of the mean $\left(n=3\right.$ ). D, Detection of $\mathrm{H}_{2} \mathrm{O}_{2}$ in Ler protoplasts transfected with either P3 or TuMV-TuR1. Ler protoplasts were transfected with GFP (control), P3, or TuMV-TuR1. Protoplasts from 4-week-old Ler plants were stained with $\mathrm{H}_{2}$ DCFDA (2'7'-dichlorofluorescin diacetate) $4.5 \mathrm{~h}$ after transfection. Images were observed using fluorescence microscopy. The fluorescent cells in one field of view were counted; counts are given on the right. $\mathrm{BF}=$ bright field; $\mathrm{DCF}=\mathrm{H}_{2}$ DCFDA. Bars $=10 \mu \mathrm{m}$. 
still remains to be answered why $\mathrm{P} 3$ proteins can participate in such host-virus interactions in common. There must be some mechanism by which numerous Potyvirus P3 proteins acquired such functions during the viral evolution.

To determine whether systemic HR is induced in the transgenic plants expressing P3, we transformed Ler or Col-0 plants with the TuR1 P3 gene and observed the phenotypes. For this construction, we used the inducible HSP 18.2 to avoid lethal necrosis at the initial stage of plant regeneration; however, it was found to be a leaky promoter and, thus, without heatshock treatment, the transgene was actually expressed to some extent. We observed yellowing with necrosis in three P3-transgenic $\mathrm{T}_{1}$ plants, and two of them died at the seedling stage. Only one $T_{1}$ plant survived, stunted and with necrotic spots on the leaves. Most of the flower buds turned yellow and eventually fell off. This phenotype was accompanied by the enhancement of accumulation level of $P R l$, indicating that the necrosis was a form of HR.

To confirm whether P3 alone can induce HR-like cell death, we also expressed P3 in protoplasts of Arabidopsis Ler and Col-0, which do and do not harbor TuNI, respectively, and found that strain-specific P3, indeed, induced HR-like cell death in Ler but not in Col-0, suggesting that P3 can independently induce HR-like cell death in the TuNI genotype without other virus-encoded proteins. This is the first demonstration that Potyvirus P3 alone works as an inducer of systemic HR. For Potyvirus spp., Agrobacterium spp.-mediated transient expression of NIa and NIb has been previously used to induce HR in potato and tobacco, respectively (Mestre et al. 2000; Fellers et al. 2002). However, Agrobacterium cells could not be used for Arabidopsis because bacterial infiltration alone caused cell death 3 to 4 days after infiltration. In addition, we cannot exclude the possibility that Agrobacterium infection per se may affect the HR induced by P3. Here, using the protoplast system, we successfully demonstrated that transient expression of strain-specific TuMV P3 in Ler cells could lead to HR-like defense reaction. Estimated by the GFP fluorescence expressed by the transfected plasmid construct, the average transfection efficiency was approximately $60 \%$. In our protoplast system, the survival rate after polyethylene glycol (PEG) treatment was always more than $90 \%$. Therefore, the results in Figure 5 indicate that the P3 transfection could actually induce HR-like cell death in more than half of the transfected Ler protoplasts. This HR induction was quite comparable with that demonstrated in the tomato protoplasts cotransfected with the avirulence gene $A v r P t o B$ and the $R$ gene Pto (Rosebrock et al. 2007). Although domain-swapping experiments still have been a major tool to identify the function of viral genes since the first demonstration by Daubert and associates (1984), our protoplast experiments will certainly provide new information as an alternative tool to study viral gene function.

In conclusion, it is now clear that P3 alone can induce HRlike cell death in TuNI-genotype Arabidopsis. Although we have not yet identified TuNI, we suspect that one of the $R$ genes in the mapped region on Ler chromosome 1 is the most probable candidate for TuNI (Kaneko et al. 2004). When we successfully isolate TuNI from Ler, we will be able to conduct experiments to elucidate the mode of interaction between P3 and TuNI.

\section{MATERIALS AND METHODS}

\section{Plant materials and growth conditions.}

Two ecotypes of A. thaliana, Ler and Col-0, were used in these experiments. Seed were directly sown in peat pellets and grown in a growth chamber (Sanyo, Tokyo) at $21^{\circ} \mathrm{C}$ with a 12 $\mathrm{h}$ photoperiod $\left(150 \mu \mathrm{mol} / \mathrm{m}^{2} / \mathrm{s}\right)$.
TuMV isolates, construction

of chimeric viruses, and viral inoculation.

Five TuMV isolates (TuR1, Azu, TuC, Tu-2R2, and C42J) were used for the inoculation tests (Kaneko et al. 2004) (Suehiro et al. 2004). The TuR1 and Azu isolates induced necrosis in Ler while the TuC, Tu-2R2, and C42J caused mosaic symptoms (Kaneko et al. 2004). The full-length infectious clones of TuR1 and TuC, designated pTuR1 and pTuC, respectively, were constructed previously (Suehiro et al. 2004). pTuR1 and pTuC were based on the pBI121 cloning vector (Clontech, Ohtsu, Japan). The recombinant clones R1-C-CI:6K2, C-R1CI:6K2, R1-C-P3, and C-R1-P3 used in this study were constructed by Suehiro and associates (2004). Those four chimeric constructs have been shown to accumulate at the same levels as those of parental isolates in B. oleracea or Raphanus sativus plants by Western blot analysis (Suehiro et al. 2004). Other recombinant clones used in this study between pTuR1 and pTuC were mainly prepared using unique corresponding restriction sites including SalI (position 2,491), AluI (position 2,995), SnaBI (position 3.305). and XhoI (position 3.680) in the viral cDNA. Three or four fully expanded leaves of 4week-old plants were rub inoculated using Carborundum with the sap inocula from the turnip leaves infected with the TuMV isolates or constructs. For investigating viral distribution in the infected plants or leaves, tissue print blots were prepared and virus was detected with anti-TuMV antibodies according to the methods described by Kaneko and associates (2004).

\section{Plant transformation.}

The P3 sequence (1,065 bp) was amplified by RT-PCR using a pair of primers, TuR1-P3-5' (5'-CGGGATCCCGACCATG GGAACAGAGTGGGAGGATACT-3') and TuR1-P3-3' (5'-G CGAGCTCGCTATTGATGAACTACTACCTTTTCTTCA-3'). The initiation codon was added to the cDNA and inserted under the HSP 18.2 of the pTT101 (Takahashi et al. 1992). Ler and Col-0 plants were transformed by the vacuum infiltration method (Bechtold and Pelletier 1998) using the Agrobacterium tumefaciens transformant. The binary vector construct was transferred into A. tumefaciens strain EHA105 by the freezeand-thaw method (Holster et al. 1978). Transformants were selected on solid medium containing $2 \%$ sucrose supplemented with one-half Murashige and Skoog (MS) nutrients and kanamycin at $50 \mu \mathrm{g} / \mathrm{ml}$. The selected shoots were then transplanted to peat pellets and grown in a growth chamber (Sanyo). The selected transgenic Ler and Col-0 lines were designated LerP3 and Col-P3, respectively. For heat-shock treatment, plants were held at $37^{\circ} \mathrm{C}$ for $3 \mathrm{~h}$ three times every third day.

\section{Isolation of total RNA and quantification of messenger RNA.}

Total RNA was isolated by Trizol reagent (Invitrogen, Tokyo) as described previously (Kim et al. 2008). For real-time PCR, one $\mu \mathrm{g}$ of the total RNA was used as the template for cDNA synthesis. First strand of cDNA was synthesized by Takara RNA PCR Kit (Takara, Ohtsu, Japan) with oligo (dT) primer. cDNA synthesis was performed at $42^{\circ} \mathrm{C}$ for $1 \mathrm{~h}, 99^{\circ} \mathrm{C}$ for 5 min, then $4^{\circ} \mathrm{C}$. Real-time RT-PCR was carried out using a $1-\mu \mathrm{l}$ aliquot of the reaction mixture and SYBR green mixture (Takara) with a DNA Engine Opticon 2 System (MJ Research, Waltham, MA, U.S.A.). The PCR cycle was $94^{\circ} \mathrm{C}$ for $30 \mathrm{~s}$, $55^{\circ} \mathrm{C}$ for $30 \mathrm{~s}, 72^{\circ} \mathrm{C}$ for $1 \mathrm{~min}$, and $78^{\circ} \mathrm{C}$ for $2 \mathrm{~s}$. This cycle was repeated 40 times. Fluorescence quantification was carried out before and after the incubation at $78^{\circ} \mathrm{C}$ to monitor for the formation of primer-dimers. The primer pairs were P3-F-210 (5'-ATTGACCCGAAGTCTACCTGAACTC-3') and P3-R-210 (5'-TGCTTCGTCCAAGATTTGTAGATA-3') plus At- $\beta$-tubulin-4-F (5'-GAGGGAGCCATTGACAACATCTT-3') and At- 
$\beta$-tubulin-4-R, (5'-GCGAACAGTTCACAGCTATGTTCA-3'). The expression pattern of PR1 (At2g14610) was examined in an eXpress profiling multiplex RT-PCR assay as determined by Kim and associates (2008). RNA (10 ng) from Arabidopsis plants or protoplasts were used. RT-PCR was performed using the primers described in Kim and associates (2008). The gene for $\beta$-tubulin-4 (At5g44340) was also amplified as an internal control.

\section{Protoplasts assay system.}

Protoplasts were prepared from leaves of 4-week-old seedlings of Ler as described previously (Yoo et al. 2007; Shimura et al. 2008) and transfected with one of the plasmids (GFP, P3, or TuR1) using PEG-calcium-mediated transformation (Yoo et al. 2007). The cDNA clones of TuMV and P3 were inserted into the cloning site in pBI121 (Clontech) and the GFP gene was cloned in pE2113 (Mitsuhara et al. 1996). Mesophyll cells were immersed in an enzyme solution containing $1.5 \%$ Cellulase R10 (Yakult Pharmaceutical Ind., Tokyo), $0.4 \%$ Macerozyme R10 (Yakult Pharmaceutical Ind.), and $0.4 \mathrm{M}$ mannitol (Wako Pure Chemical Industries, Osaka, Japan). After incubation at room temperature for $6 \mathrm{~h}$, protoplasts were collected by centrifugation at $100 \times g$ for $2 \mathrm{~min}$, washed with W5 solution (2 mM MES [pH 5.7], $154 \mathrm{mM} \mathrm{NaCl}, 125 \mathrm{mM}$ $\mathrm{CaCl}_{2}$, and $5 \mathrm{mM} \mathrm{KCl}$ ) and then kept on ice at least for $30 \mathrm{~min}$ in fresh W5 solution. Transfection of protoplasts was performed according to the protocol of Shimura and associates (2008) with slight modifications. Briefly, protoplasts were resuspended in MMG solution (4 mM MES pH 5.7, 0.4 M mannitol, and $15 \mathrm{mM} \mathrm{MgCl}_{2}$ ) to a density of $2 \times 10^{5}$ protoplasts $/ \mathrm{ml}$, and $100 \mu \mathrm{l}$ of protoplast suspension was mixed with plasmids in $110 \mu \mathrm{l}$ of PEG-calcium transfection solution $(35 \%$ [wt/vol] PEG 4000, 0.2 M mannitol, and 0.1 $\mathrm{M} \mathrm{CaCl}_{2}$ ). After incubation for $15 \mathrm{~min}$, the transfection mixture was diluted with 440 $\mu \mathrm{l}$ of cold W5 solution and mixed well and centrifuged at 100 $\times g$ for 2 min; then, the supernatant was removed. Protoplasts were transfected with $10 \mu \mathrm{g}$ of vector DNA and incubated at room temperature $\left(20\right.$ to $\left.25^{\circ} \mathrm{C}\right)$ in WI solution (4 mM MES [pH 5.7], 0.5 M mannitol, and $20 \mathrm{mM} \mathrm{KCl}$ ). Protoplast cell death was assessed with Evans blue (0.04\%) staining $20 \mathrm{~h}$ after transfection, as described previously (Rosebrock et al. 2007). Our average transfection efficiency was approximately $60 \%$. We counted the number of dead cells in several fields at $\times 400$ magnification. Protoplasts were exposed to the dye for 5 min, then observed with light microscopy (Olympus BX51; Olympus, Tokyo). $\mathrm{H}_{2} \mathrm{O}_{2}$ signals were visualized with $\mathrm{H}_{2}$ DCFDA (Sigma, St. Louis) $4 \mathrm{~h}$ after transfection. $\mathrm{H}_{2}$ DCFDA was dissolved in dimethyl sulfoxide so that the final concentration was adjusted to $500 \mathrm{nM}$. The images were observed with a fluorescence microscope (Leica DMI 6000B; Leica, Tokyo) and $\mathrm{H}_{2}$ DCFDA signals were visualized with excitation at 488 nm (emission: 498 to $532 \mathrm{~nm}$ ).

\section{Enzyme-linked immunosorbent assay for viral detection in protoplasts.}

To confirm the virus infection in the protoplasts transfected with pTuR1, we used enzyme-linked immunosorbent assay and the double-antibody sandwich method in a 96-well microplate with the alkaline phosphatase conjugate system. Each well was then coated with the coating antibody in carbonate buffer ( $\mathrm{pH}$ 9.6) and incubated in an incubator for $3 \mathrm{~h}$ at $37^{\circ} \mathrm{C}$ or overnight at $4^{\circ} \mathrm{C}$. After washing four times with phosphatebuffered saline-Tween (PBST) buffer ( $8 \mathrm{~g}$ of $\mathrm{NaCl}, 2.9 \mathrm{~g}$ of $\mathrm{Na}_{2} \mathrm{HPO}_{4} \cdot 12 \mathrm{H}_{2} \mathrm{O}, 0.2 \mathrm{~g}$ of $\mathrm{KH}_{2} \mathrm{PO}_{4}, 0.2 \mathrm{~g}$ of $\mathrm{KCl}$, and $0.5 \mathrm{ml}$ of Tween-20 in 1 liter of $\left.\mathrm{H}_{2} \mathrm{O}\right)$, sample extracts $(200 \mu \mathrm{l} /$ well $)$ from $2 \times 10^{4}$ protoplasts $14 \mathrm{~h}$ after transfection with pTuR1 were dispensed to each well. After the plate was kept overnight at $4{ }^{\circ} \mathrm{C}$, it was washed with PBST, and then each well was coated with the AP-conjugated antibodies and incubated for $3 \mathrm{~h}$ at $37^{\circ} \mathrm{C}$. After washing four times with PBST, p-nitrophenyl phosphate disodium solution in $10 \%$ diethanolamine was added to each well, and the plate was incubated for $1 \mathrm{~h}$ at room temperature. After incubation, absorbance was measured at $405 \mathrm{~nm}$ with a Wallac ARVO MX immunoreader (Perkin Elmer Japan, Yokohama, Japan).

\section{ACKNOWLEDGMENTS}

This work was supported in part by a Grant-in-Aid for Scientific Research (C) from Japan Society for the Promotion of Science. We thank H. Shimura, K. Sueda, A. Fujiwara, and J. Sato for their kind technical advice.

\section{LITERATURE CITED}

Bechtold, N., and Pelletier, G. 1998. In planta Agrobacterium-mediated transformation of adult Arabidopsis thaliana plants by vacuum infiltration. Methods Mol. Biol. 82:259-266.

Chung, B. Y., Miller, W. A., Atkins, J. F., and Firth, A. E. 2008. An overlapping essential gene in the Potyviridae. Proc. Natl. Acad. Sci. U.S.A. 105:5897-5902.

Daubert, S. D., Schoelz, J., Debao, L., and Shepherd, R. J. 1984. Expression of disease symptoms in Cauliflower mosaic virus genomic hybrids. J. Mol. Appl. Genet. 2:537-547.

Fellers, J. P., Tremblay, D., Handest, M. F., and Lommel, S. A. 2002. The Potato virus $Y \mathrm{M}^{\mathrm{s}} \mathrm{N}^{\mathrm{r}} \mathrm{NIb}$-replicase is the elicitor of a veinal necrosis-hypersensitive response in root knot nematode resistant tobacco. Mol. Plant Pathol. 3:145-152.

Gal-On, A. 2000. A point mutation in the FRNK motif of the potyvirus helper component-protease gene alters symptom expression in cucurbits and elicits protection against the severe homologous virus. Phytopathology 90:467-473.

Hajimorad, M. R., Eggenberger, A. L., and Hill, J. H. 2005. Loss and gain of elicitor function of Soybean mosaic virus G7 provoking Rsv1-mediated lethal systemic hypersensitive response maps to P3. J. Virol. 79:1215-1222.

Hajimorad, M. R., Eggenberger, A. L., and Hill, J. H. 2006. Strain-specific P3 of Soybean mosaic virus elicits Rsv1-mediated extreme resistance, but absence of P3 elicitor function alone is insufficient for virulence on Rsv1-genotype soybean. Virology 345:156-166.

Hajimorad, M. R., Eggenberger, A. L., and Hill, J. H. 2008. Adaptation of Soybean mosaic virus avirulent chimeras containing P3 sequences from virulent strains to Rsv1-genotype soybeans is mediated by mutations in HC-Pro. Mol. Plant-Microbe Interact. 21:937-946.

Holsters, M., De Waele, D., Depicker, A., Messens, E., Van Montagu, M., and Schell, J. 1978. Transfection and transformation of Agrobacterium tumefaciens. Mol. Gen. Genet. 163:181-187.

Jenner, C. E., Sánchez, F., Nettleship, S. B., Foster, G. D., Ponz, F., and Walsh, J. A. 2000. The cylindrical inclusion gene of Turnip mosaic virus encodes a pathogenic determinant to the Brassica resistance gene TuRB01. Mol. Plant-Microbe Interact. 13:1102-1108.

Jenner, C. E., Tomimura, K., Ohshima, K., Hughes, S. L., and Walsh, J. A. 2002. Mutations in Turnip mosaic virus P3 and cylindrical inclusion proteins are separately required to overcome two Brassica napus resistance genes. Virology 300:50-59.

Jenner, C. E., Wang, X., Tomimura, K., Ohshima, K., Ponz, F., and Walsh, J. A. 2003. The dual role of the potyvirus P3 protein of Turnip mosaic virus as a symptom and avirulence determinant in brassicas. Mol. PlantMicrobe Interact. 16:777-784.

Kaneko, Y.-H., Inukai, T., Suehiro, N., Natsuaki, T., and Masuta, C. 2004. Fine genetic mapping of the TuNI locus causing systemic veinal necrosis by Turnip mosaic virus infection in Arabidopsis thaliana. Theor. Appl. Genet. 110:33-40.

Kim, B., Masuta, C., Matsuura, H., Takahashi, H., and Inukai, T. 2008. Veinal necrosis induced by Turnip mosaic virus infection in Arabidopsis is a form of defense response accompanying HR-like cell death. Mol. Plant-Microbe Interact. 21:260-268.

Mestre, P., Brigneti, G., and Baulcombe, D. C. 2000. An Ry-mediated resistance response requires the intact active site of the NIa proteinase from Potato virus Y. Plant J. 23:653-661.

Mitsuhara, I., Ugaki, M., Hirochika, H., Ohshima, M., Murakami, T., Gotoh, Y., Katayose, Y., Nakamura, S., Honkura, R., Nishimiya, S., Ueno, K., Mochizuki, A., Tanimoto, H., Tsugawa, H., Otsuki, Y., and Ohashi, Y. 1996. Efficient promoter cassettes for enhanced expression 
of foreign genes in dicotyledonous and monocotyledonous plants. Plant Cell Physiol. 37:49-59.

Redondo, E., Krause-Sakate, R., Yang, S. J., Lot, H., Gall, O. L., and Candresse, T. 2001. Lettuce mosaic virus pathogenicity determinants in susceptible and tolerant lettuce cultivars map to different regions of the viral genome. Mol. Plant-Microbe Interact. 14:804-810.

Rosebrock, T. R., Zeng, L., Brady, J. J., Abramovitch, R. B., Xiao, F., and Martin, G. B. 2007. A bacterial E3 ubiquitin ligase targets a host protein kinase to disrupt plant immunity. Nature 448:370-374.

Sáenz, P., Cervera, M. T., Dallot, S., Quiot, L., Quiot, J. B., Riechmann, J. L., and García, J. A. 2000. Identification of a pathogenicity determinant of Plum pox virus in the sequence encoding the C-terminal region of protein P3+6K(1). J. Gen. Virol. 81:557-566.

Sáenz, P., Quiot, L., Quiot, J. B., Candresse, T., and Garcia, J. A. 2001. Pathogenicity determinants in the complex virus population of a Plum pox virus isolate. Mol. Plant-Microbe Interact. 14:278-287.

Shattuck, V. I. 1992. The biology, epidemiology and control of Turnip mosaic virus. J. Janick, ed. Plant Breed. Rev. 14:199-238.

Shimura, H., Fukagawa, T., Meguro, A., Yamada, H., Oh-Hira, M., Sano, S., and Masuta, C. 2008. A strategy for screening an inhibitor of viral silencing suppressors, which attenuates symptom development of plant viruses. FEBS (Fed. Eur. Biol. Soc.) Lett. 582:4047-4052.

Shukla, D. D., Frenkel, M. J., and Ward, C. W. 1991. Structure and function of the potyvirus genome with special reference to the coat protein coding region. Can. J. Plant Pathol. 13:178-191.
Shukla, D. D., Ward, C. W., and Brunt, A. A. 1994. The Potyviridae. CAB International, Wallingford, U.K.

Suehiro, N., Natsuaki, T., Watanabe, T., and Okuda, S. 2004. An important determinant of the ability of Turnip mosaic virus to infect Brassica spp. and/or Raphanus sativus is in its P3 protein. J. Gen. Virol. 85:20872098.

Takahashi, T., Naito, S., and Komeda, Y. 1992. The Arabidopsis HSP18.2 promoter/GUS gene fusion in transgenic Arabidopsis plants: a powerfu tool for the isolation of regulatory mutants of the heat-shock response. Plant J. 2:751-761.

Tomlinson, J. A. 1987. Epidemiology and control of virus diseases of vegetables. Ann. Appl. Biol. 110:661-681.

Walsh, J. A., and Jenner, C. E. 2002. Turnip mosaic virus and the quest for durable resistance. Mol. Plant Pathol. 3:289-300.

Walsh, J. A, Rusholme, R. L, Hughes, S. L, Jenner, C. E., Bambridge, J M., Lydiate, D. J., and Green, S. K. Different classes of resistance to Turnip mosaic virus in Brassica rapa. 2002. Eur. J. Plant Pathol. 108:15-20.

Ward, C. W., Weiller, G. F., Shukla, D. D., and Gibbs, A. 1995. Molecular systematics of the Potyviridae, the largest plant virus family. Pages 477 500 in: Molecular Basis of Virus Evolution. A. Gibbs, C. H. Calisher, and F. Garcia-Arenal, eds. Cambridge University Press, Cambridge.

Yoo, S. D., Cho, Y. H., and Sheen, J. 2007. Arabidopsis mesophyll protoplasts: a versatile cell system for transient gene expression analysis. Nat. Protoc. 2:1565-1572. 